\title{
AN ATTEMPT TO EXPLAIN THE EFFECT OF CLIMATE ON THE ACTION OF AN ESTHETICS.
}

\author{
By C. F. MOORE, M.D., F.R.C.S.; \\ Late Medical Officer, No. 3 District, South Dublin Union.
}

[Read in the Section of Medicine, Nov. 20, 1891.]

ON reading the following in the first volume of the Reports of the Proceedings of the International Medical Congress of last year, I was led to consider that the effect of climate was not altogether explained by the greater readiness with which the chloroform vapour was dissipated in hot climates is compared with its condition in cooler latitudes.

Dr. Horatio C. Wood observes, at p. 140:-“A very curious parallel might be traced at this point between the experimental and clinical evidence in regard to the effect of climate upon the action of chloroform. In the Southern United States rhloroform is used with great freedom, and with great alleged safety; and as long ago as 1878 Dr. Langdon B. Edwards, editor of the Virginia Medical Monthly, wrote-' It is one of the most peculiar facts I have ever known in medical practice, the difference of experience in Europe and the north, with chloroform and ether, as comfared with that of the south, the high rate of mortality in the north and the low rate of the south. Further, in a recent letter to me, Sir Joseph Fayrer is very emphatic as to the safety of chloroform in India." "

The very important and interesting paper of Dr. Wood has led me to bring forward this subject before the Royal Academy of Medicine, with a view to elicit opinion, and to isk those whose modern training, whose leisure and opportunities of research, and whose abilities fit them for a full and 
searching inquiry into this-at matter of great interest and importance.

The point which struck me as bearing on the subject of this paper, in addition to those advanced by Dr. Wood, is that in hot climates the lungs play a comparatively less important part than they do in temperate and colder regions, and that, therefore, in the latter interference with their function, as in inhalation of chloroform, is more apt to be attended by serious consequences than in warmer latitudes, partly owing, as Dr. Wood advances, to the warm climate rendering the vapour of chloroform more easily diffused than at a lower temperature.

It is, I think, self-evident that the inhabitants of warmer regions are more independent of the action of their lungs than those of cooler latitudes, hence the greater endurance of the former in rumning and other like exercises; whereas the liver and skin seem to me to be of relatively greater importance in the persons of those who inhabit warm latitudes. This idea I do not regard as at rariance with the views of Dr. Wood, Dr. Lauder Brunton, and others, and merely offer it as a suggestion in explanation as to the alleged greater safety in the use of chloroform in warm climates, in addition to that given by Dr. Wood of the greater diffusibility of chloroform vapour in the latter. Ether, on the other hand, being so much more readily diffusible, is not relatively so much affected by climate.

The British Medical Journal, Sept. 13, 1890, speaks of cases where the muscular walls of the heart and the hepatic cells were affected with fatty degeneration, from, as was considered by Professor Thierre, the somewhat prolonged use of chloroform-the patient in one case having been under its influence for more than one hour and a half. This man, though robust and temperate, and only thirty-six, was operated on for fractured patella by suture. 
Animals kept under chloroform-especially when the dose was repeated for two or three days-were found to have the heart and liver changed in a similar way.

I introduce the foregoing to warn my hearers that although chloroform appears safer in general in warm latitudes, yet if its application be long continued, or often resorted to. another danger arises as just mentioned-a danger which we may infer to be more real and likely in warm climates than in those that are temperate or cold.

The Second Hyderabad Chloroform Commission ${ }^{\text {a }}$ reported as necessary to safety in chloroform administration, the recumbent position on the back, and perfect freedom of respiration, and strict and continuous attention to the condition of respiration as the most essential part of its administration-in fact, as far more necessary than observation of the state of the heart.

It would appear that such being the experience of able, practical, and scientific physicians in warm climates, those who use this potent agent in temperate and in cold region: should be doubly observant of these and other very full and important recommendations of the Commission, and of the very valuable observations of $\mathrm{Dr}$. $\mathrm{H}$. Wood, as published in the Proceedings of the Berlin Congress.

On referring to the work of $\mathrm{Mr}$. Bryant, I find in corroboration of what I have quoted above from Dr. Wood's paper, that he says:- "In the more threatening cases commence instantly with artificial respiration, whether the respiration has failed alone, or the pulse and respiration together." $\mathrm{b}$

Dr. Wood ${ }^{\mathrm{c}}$ shows the injurious effects of attempting to counteract the poisonous influence of chloroform or

a Lancet. Vol. I., p. 158, \&c. 1890.

b Vol. II., p. 538. Second Edition.

${ }^{c}$ Report of International Medical Congress, 1891. Vol. I., p. 146-7, \&c. 
ether inhalation by alcoholic or etherial remedies howerer administered.

Digitalis, either before administration of chloroform, or after its effects have become injurious, he considers to have saved life in his experiments on dogs, and he "believes that in all cases of weak heart in man a full dose of digitalis before the administration of chloroform would greatly lessen the danger of cardiac collapse." Strychnine, and above all, artificial respiration, are what he has been led to regard the real remedies against death from chloroform.

The treatment of threatened danger from chloroform hardly comes within the scope of the present paper, as I originally intended it; but on the principle that some have held that the disease is to some extent to be known by the remedy, I thought it well to introduce some remarks and quotations on the subject.

As advanced by Dr. Wood, it has an importance in explanation of the greater safety of chloroform when used by inhalation in the tropics and other warmer latitudes than in the colder regions.

It is not out of place to advert to the influence which a warm climate, especially if it be also dry, as described by the late Sir James Clark, exercises "on almost all the functions of the animal economy, but more especially its obrious agency in promoting an equable distribution of the circulating fluids over the whole system, and particularly its effect in augmenting the activity of the circulation in the capillaries of the surface, and in diminishing in the same proportion the congestion of the internal vessels," and further on the same eminent authority continues-"If we take into account also the effect of the continual action of a bland atmosphere on the extensive surface of the respiratory organs, both as abating irritation of the lungs, and enabling them more

a Cyclopædia of Practical Medicine. Vol. I., p. 419. 
effectually to produce those changes in the blood that are essential to health, we have another very obvious explanation of the results observed."

It is hardly within the scope of this brief sketch to more than allude to what the late eminent Professor Casper ${ }^{a}$ termed chronic chloroform poisoning.

In such cases he held that hours, days, or even weeks may elapse, "during which the person anæsthetised remains continuously under the influence of the poison to which he at length succumbs." I may observe that most of the fatal cases investigated by Professor Casper occurred in cold weather.

The position which I believe to be borne out by the experience of those who have used shloroform in hot climates extensively, and which Dr. Wood puts forward, that it is a more safe anæsthetic when used there than when used in colder regions, is further borne out by what Dr. Wood records, and what I have myself ascertained, that the cat's reputed "nine lives" stands to it when subjected to chloroform inhalation.

Now the cat under almost all conditions lives, at least the domestic cat, in what approaches very nearly to a warm climate-I think everyone will admit this-much more so at all events than the average dog, at least such of the latter as are likely to be experimented on; and therefore this circumstance seems to bear out the position that I assumeto wit, that chloroform is more safe in hot climates than in cold, because the lungs, which are so seriously compromised in inhalation, are comparatively less important in high temperatures than in low. This fact is aided by the greater diffusibility of chloroform in the more elevated temperature, and the more active discharge of the functions of the skin and liver.

a Casper's Forensic Medicine. Vol. II., p. 296. New Sydenham Society. 
24 Effect of Climate on the Action of Ancesthetics.

Dr. Frazer wished to say he had seen the first case of ether administration in Europe at the Richmond Hospital, and had given the first dose of chloroform at the same hospital to a patient of Mr. John Hamilton's. He had for a long time administered it at operations, and never had a single accident, which he attributed to giving his undivided attention to the exhibition of the anæsthetic. He had, however, in private practice met two cases of serious symptoms, both fortunately ending favourably; these were not due to the anasthetic but to syncope occurring in various individuals as the effects of the anxsthetic passed off. He had to direct attention to the fact that some persons eliminated the anæsthetic more slowly than others; in one case, for example, the vapour of ether continued to pass off for at least three days. Under the late Sir D. Corrigan he had given it in many cases of delirium tremens, and the result was such that the practice was abandoned, serious symptoms invariably occurring, but none ending fatally. As for continued administration in a case of tetanus, he had aided in using it for upwards of two days; the chloroform gave relief, and enabled the patient to take food, but the disease progressed and ended fatally.

Dr. Moork, in reply, agreed with Dr. Frazer's remarks as adding to the interest in the subject, and stated that he was well aware that it was only in exceptional circumstances, as in Calcutta, that ether could be had in a warm climate. 